\title{
Switchable Quad-Band Antennas for Cognitive Radio Base Station Applications
}

\author{
Terence Wu, Student Member, IEEE, Rong Lin Li, Senior Member, IEEE, Soon Young Eom, Member, IEEE, \\ Seong Sik Myoung, Student Member, IEEE, Kyutae Lim, Member, IEEE, Joy Laskar, Fellow, IEEE, \\ Soon Ik Jeon, and Manos M. Tentzeris, Senior Member, IEEE
}

\begin{abstract}
A novel antenna configuration for quad-band operation is presented. The quad-band antenna has a directional radiation pattern in four frequency bands, i.e., B1 (800-900 MHz), B2 (1.7-2.5 GHz), B3 (3.3-3.6 GHz), and B4 (5.1-5.9 GHz), covering all spectrums for existing wireless applications, such as GSM, PCS, WCDMA, WiFi, and WiMax. The operating frequency of the quad-band antenna can be adjusted by the use of a MEMS switch, making it suitable for cognitive radio applications. First a switchable quad-band antenna element is introduced. Then a two-element antenna array is developed to increase the antenna gain for base station applications featuring a gain value of about 9-11 dBi over all four frequency bands.
\end{abstract}

Index Terms-Base station antenna, cognitive radio, quad-band antenna, switchable antenna.

\section{INTRODUCTION}

W ITH the increasing demand for wireless connectivity, the radio frequency spectrum is getting more and more crowded with applications satisfying communication needs for public, private, and government sectors. The spectrum congestion increases the cost of spectrum licensing, which ultimately leads to a higher cost per bit for each user. Cognitive radio aims to reduce spectrum congestion by sensing unused bandwidth in the existing communication standards and opportunistically maximizes the spectrum utilization for the end user [1]. In the public communication sector, several bands are allocated to existing standards, such as GSM, PCS, WCDMA, WiFi, and the recently adopted WiMax worldwide. It is advantageous to provide cognitive radio services that maximize the data delivery

Manuscript received April 20, 2009; revised September 22, 2009; accepted November 16, 2009. Date of publication March 01, 2010; date of current version May 05, 2010. This work was supported by the IT R\&D program of MKE/IITA [2007-F-041-01, Intelligent Antenna Technology Development].

T. Wu, K. Lim, J. Laskar, and M. M. Tentzeris are with the School of Electrical and Computer Engineering, Georgia Institute of Technology, Atlanta, GA 30308 USA (e-mail: twu@ece.gatech.edu; ktlim@ece.gatech.edu; joy.laskar@ece.gatech.edu; etentze@ece.gatech.edu).

R. L. Li is with the School of Electronic and Information Engineering, South China University of Technology, Guangzhou 510641, China and also with the School of Electrical and Computer Engineering, Georgia Institute of Technology, Atlanta, GA 30308 USA. (e-mail: lirl@ scut.edu.cn).

S. S. Myoung was with Dept. of Electrical and Electronic Engineering, Yonsei University, Seoul 120-749, Korea and also with the School of Electrical and Computer Engineering, Georgia Institute of Technology, Atlanta, GA 30308 USA. He is now with Samsung Electronics Inc., Seoul 137-857, South Korea (e-mail: myoungss@yonsei.ac.kr).

S. Y. Eom and S. I. Jeon are with the Electronics and Telecommunications Research Institute, Yuseong-gu, Daejeon, 305-700, Korea.

Color versions of one or more of the figures in this paper are available online at http://ieeexplore.ieee.org.

Digital Object Identifier 10.1109/TAP.2010.2044472 across those existing communication standards utilizing a single base station antenna system.

To support the comprehensive and intelligent communication offered by cognitive radio architecture, a new paradigm of RF front-end is needed [2]. Due to wide spectral bandwidth utilization, reducing interference between the radios is critical in improving their signal to noise ratio and the overall spectrum usage. Thus RF front-ends need to limit its instantaneous dynamic range to avoid non-linear distortion in the desired channel [3]. Several authors have proposed antenna structures that would reduce antennas' dynamic range by the use of switches [4]-[11]. Switchable antennas can be realized using electronic switches, such as varactor diodes or MEMS switches. Three types of switchable/reconfigurable antennas have been implemented in the literature: polarization [4], [5], spectral [5]-[9], and spatial [8]-[11]. For base station antennas, spatial and spectral sensing are the two areas of interest.

In traditional base stations, several antenna techniques have been established to enhance system capacity. 1) The antenna is positioned with its E plane perpendicular to earth surface to utilize ground reflections for increasing signal range. 2) To eliminate co-channel interference between adjacent towers and increase spectrum reuse, spatial sectoring is implemented in the antenna's $\mathrm{H}$ plane. Horizontal beam width typically varies between $60^{\circ}, 90^{\circ}, 120^{\circ}, 180^{\circ}$, to $360^{\circ}$ depending on the number of sectors deployed [12]. 3) To further reduce the co-channel interference between adjacent towers and enhance signal strength towards the mobile device, a narrow vertical beam width ranging from $7^{\circ}$ to $20^{\circ}$ with beam tilting is desired. Thus an antenna array needs to be extended vertically along its E plane. Such array implementation is difficult to achieve in frequency agile antenna designs since the electrical element spacing for each frequency band must be almost the same in wavelengths to avoid grating lobes. Grating lobe and side lobe formation results in large signal variation in the service area, and should be reduced unless the system can spatially reconfigure the null position to its advantage. Due to grating lobe considerations, most existing directional multi-band antennas cannot be easily extended to array configurations along their E plane, because these antennas share the same radiating element at different frequency bands [5], [9], [13]-[15].

In this paper, a switchable multi-band two radiator element is introduced and optimized to offer a sectored radiation pattern in four frequency bands: $800-900 \mathrm{MHz}$ (B1), $1.7-2.5 \mathrm{GHz}$ (B2), 3.3-3.6 GHz (B3), and 5.1-5.9 GHz (B4), used for GSM, PCS, WCDMA, WiFi and WiMAX systems. This quad-band two radiator architecture is "arrayable" because the radiating 


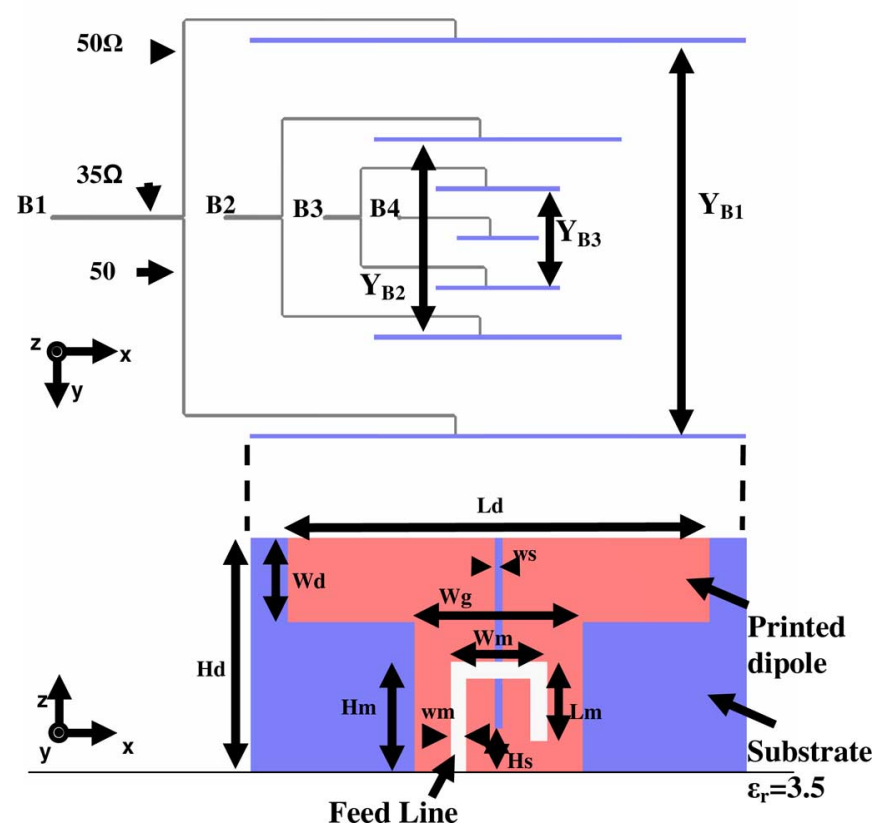

Fig. 1. Configuration of a quad-band antenna element.

elements for each frequency bands can be readjusted along its E plane. Its two element array will be presented to demonstrate the possibility of beam width narrowing and beam tilting along its E plane, as desired by base stations. Furthermore, this quad-band antenna geometry has a compact form factor and high scalability to incorporate additional frequency bands in the future. Design and measurement results for the quad-band antenna element are first introduced, followed by a description of the system level requirement and the design process of the quad-band array.

\section{QUAD-BAND Two RADIATOR ELEMENT}

The configuration of the proposed switchable quad-band antenna element is shown in Fig. 1. For B1, B2, and B3, there is a pair of symmetrically positioned dipole arms in the $y$ direction. The separation between the dipole arms is approximately $0.5 \lambda$ with $\lambda$ being the free-space wavelength at the center frequency for each frequency band. Only a single dipole is used for B4 because it is located exactly in the center of symmetry. The dipole arm selected was based on "the printed broadband dipole antenna with integrated balun" documented in [16]-[20]. It provides a simple broadband dipole structure with the capability to easily tune the impedance matching. With this structure, the radiation pattern of the quad-band antenna can be easily controlled by the relative position of the dipole arms and the dipole length, while the impedance matching is individually controlled by the balun matching network.

The quad-band antenna has four ports as indicated in Fig. 1, and is designed to be controlled by a TeraVicta SP4T MEMS switch. A schematic of the MEMS switch system is shown in Fig. 2, which includes a front-end amplifier (RFA), a digital controller, and an SP4T MEMS switch. The MEMS switch implementation is an active area of research because it offers lower loss, high isolation, and high linearity desired by the in RF front

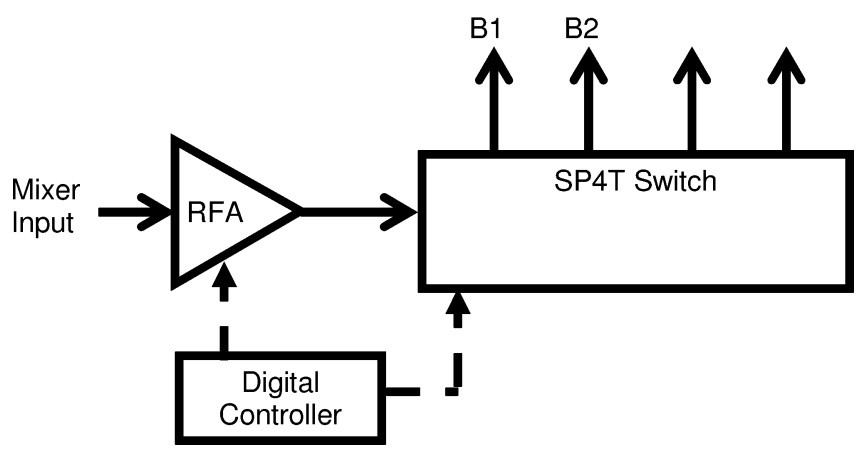

Fig. 2. A schematic of a switch system for the quad-band antenna element.

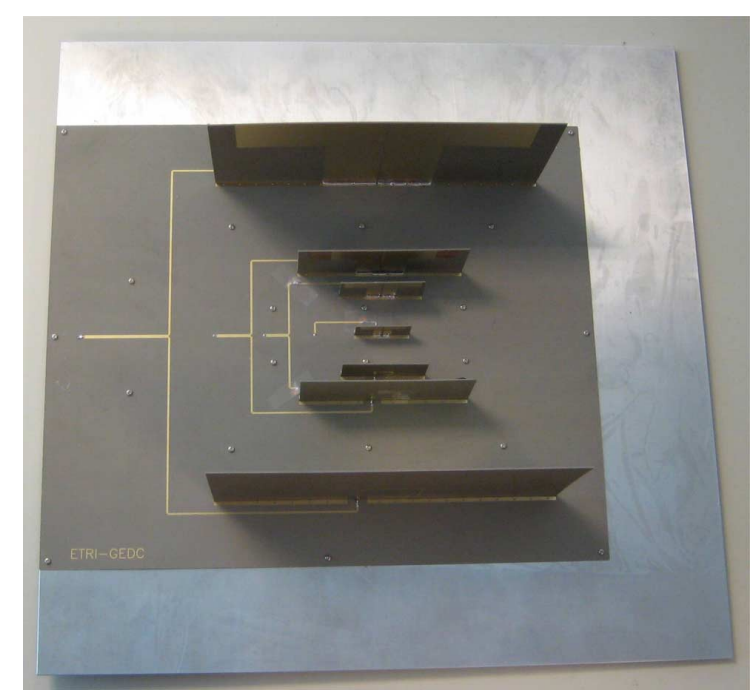

Fig. 3. A prototype of the quad-band antenna element.

end [21]. In this paper, the switch performance will not be covered and an ideal switch is assumed to be connected to the ports of the quad-band antenna element.

The antenna was designed using Microstripes 7.5, a TLM based commercial solver, with a Taconic RF35 substrate of $\varepsilon_{\mathrm{r}}=3.5$ and loss tangent $=0.0018$. The dipole arms were designed on 30 mils $(0.762 \mathrm{~mm})$ substrate to provide better mechanical stability for standing perpendicular to the ground, while the base board was designed on 20 mils $(0.508 \mathrm{~mm})$ to allow narrower feeding lines on board. A feeding network was designed for each frequency band, and $35 \Omega$ quarter wavelength transformers were used to split the input power into two $50 \Omega$ antenna loads. To mimic the behavior of the MEMS switch, non-active ports were left as open circuits in both simulations and measurements. A prototype of the quad-band antenna element is pictured in Fig. 3. A $400 \mathrm{~mm} \times 400 \mathrm{~mm}$ ground plane was used to support the quad-band antenna. The optimized dipole arms dimensions and dipole spacing are listed in Table I. The optimization was done in a three stage process: 1) radiation pattern and matching of individual dipole arms are simulated in the four frequencies of interest, 2) the H-plane radiation pattern is optimized by adjusting relative spacing of the dipole, and 3) the balun transition of each dipole arm is readjusted to tune the impedance after including the affects of radiator spacing and feeding network. 
TABLE I

DimENSIONS OF THE QUAD-BAND ANTENNA ELEMENT (MM)

\begin{tabular}{ccccc}
\hline \hline Dimensions & B1 & B2 & B3 & B4 \\
\hline Hd & 95 & 40 & 25.2 & 15 \\
Ld & 170 & 76 & 45.6 & 27 \\
wd & 34 & 15 & 9 & 5.5 \\
wg & 68 & 30 & 18 & 11 \\
ws & 1 & 1 & 1 & 1 \\
Hs & 0 & 0 & 0 & 0 \\
Hm & 39.7 & 19.7 & 9.7 & 5.5 \\
wm & 1.7 & 1.7 & 1.7 & 1.7 \\
Wm & 36 & 16 & 11.6 & 8 \\
Lm & 26.7 & 10.7 & 3.7 & 4.5 \\
Y & 200 & 80 & 50 & 0
\end{tabular}

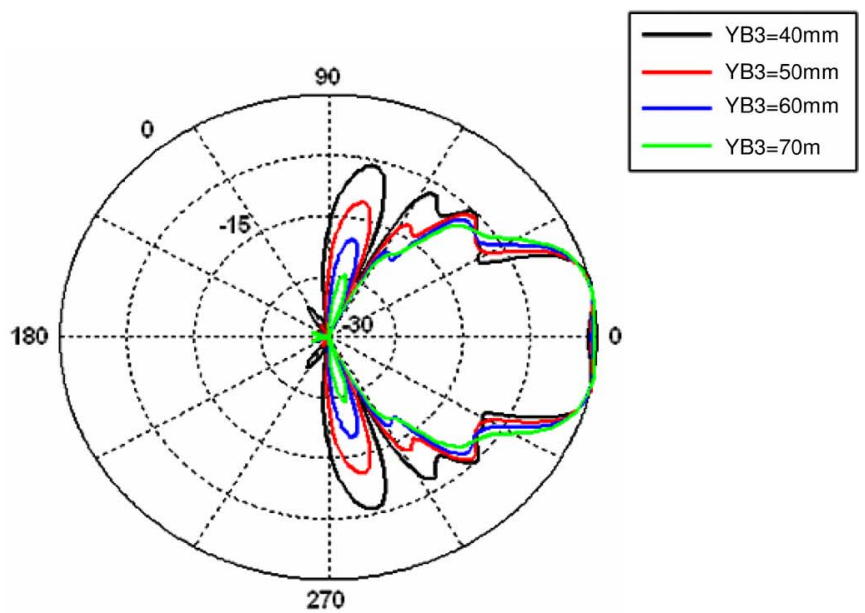

(a)

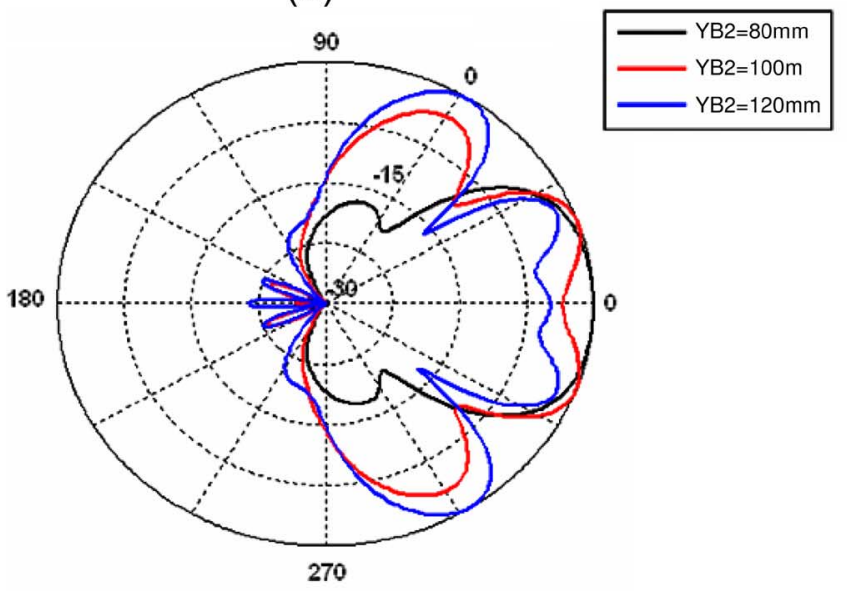

(b)

Fig. 4. H-plane Radiation affected by (a) adjacent lower frequency dipoles, effect of $\mathrm{Y}_{\mathrm{B} 3}$ on $\mathrm{B} 4$ at $5.5 \mathrm{GHz}$, (b) grating lobe, effect of $\mathrm{Y}_{\mathrm{B} 2}$ on $\mathrm{B} 2$ at $2.4 \mathrm{GHz}$

To design the individual dipole arm, $L d$ of $0.5 \lambda$ was chosen for the printed dipole length elevated $0.25 \lambda$ above the ground plane $(H d)$. The dipole width $W d$, which is half of $W g$ for impedance matching, needs to be at least 3 times greater than wm, the feed line width. This allows microstrip mode of the feed line, and constant impedance between the ground to the radiating dipole ends. By selecting $H s=0$, and mainly adjusting

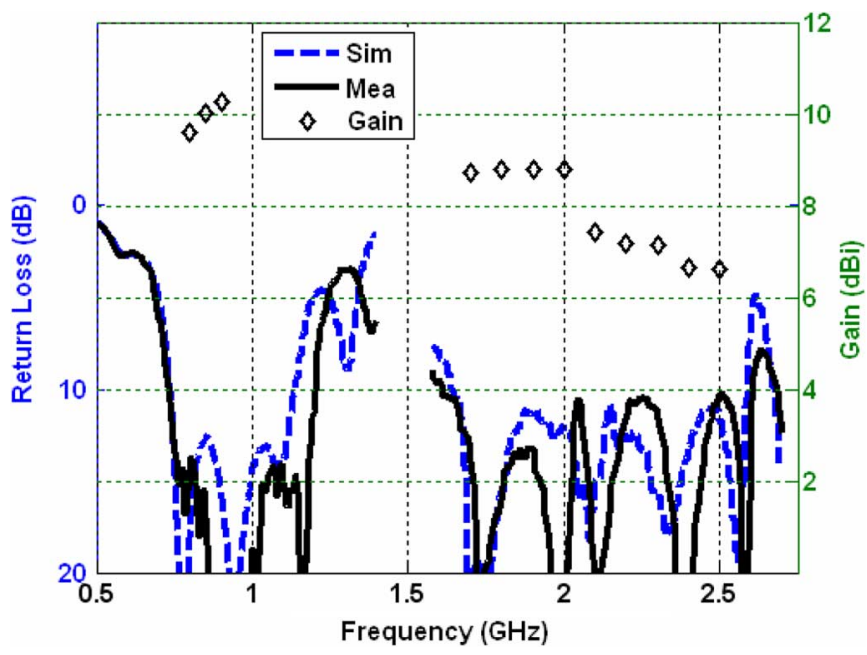

Fig. 5. Simulated and measured return loss with measured gain of the quadband antenna element in B1 and B2.

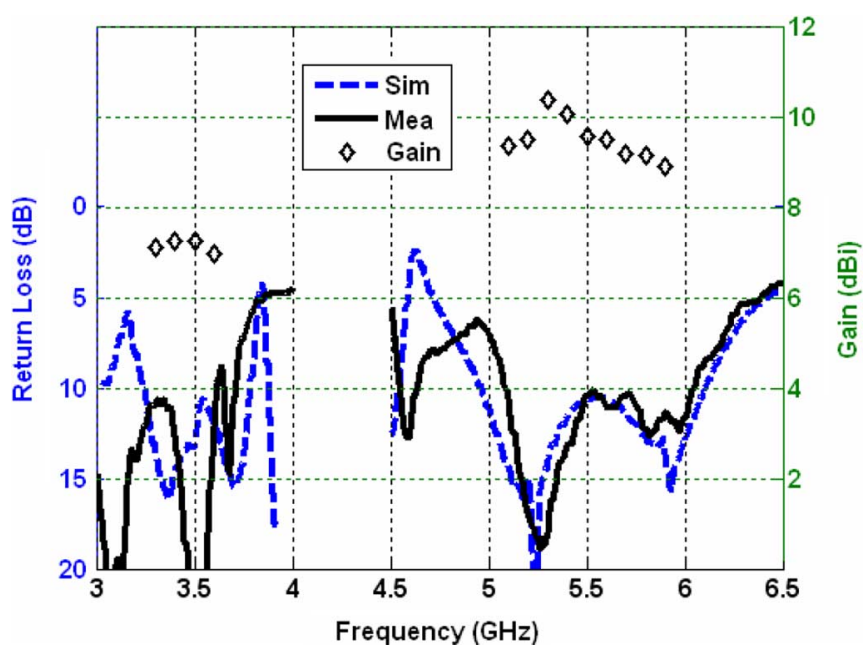

Fig. 6. Simulated and measured return loss with measured gain of the quadband antenna element in B3 and B4.

$H m$ and $L m$, a wideband impedance match is obtained for a single frequency band. Alternatively, the dimensions in [16], optimized for B2 operation, can be resized for the other three bands.

The goal of radiation optimization is to reduce drastic variations of the $\mathrm{H}$ plane pattern within the $10 \mathrm{~dB}$ beam width by changing the radiator spacing, $Y$. Sidelobe-level at the higher-frequencies $\mathrm{H}$-plane and grating-lobe formation at the lower frequencies $\mathrm{H}$-plane are the radiation performance tradeoffs when adjusting this parameter. High frequency sidelobes are caused by excessively decreasing the spacing between the adjacent lower frequency elements, thus increasing the coupling between the dipoles and exciting more higher-order modes. To illustrate this effect, Fig. 4(a) shows the increasing sidelobe level and null formation at B4 due to the decreasing spacing of $Y_{B 3}$. By increasing the adjacent dipole spacing, the sidelobes can be reduced, but grating lobes may emerge for these adjacent dipoles if the $\mathrm{H}$ plane spacing between the same frequency radiators well exceeds $0.5 \lambda$ [22]. The grating lobe 


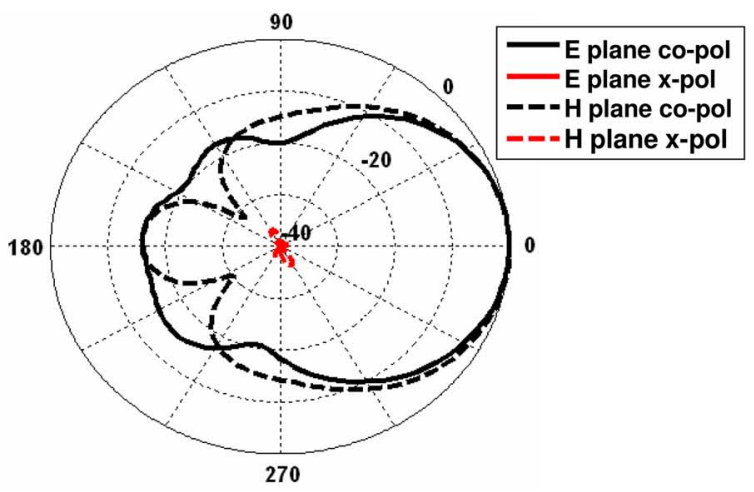

(a)

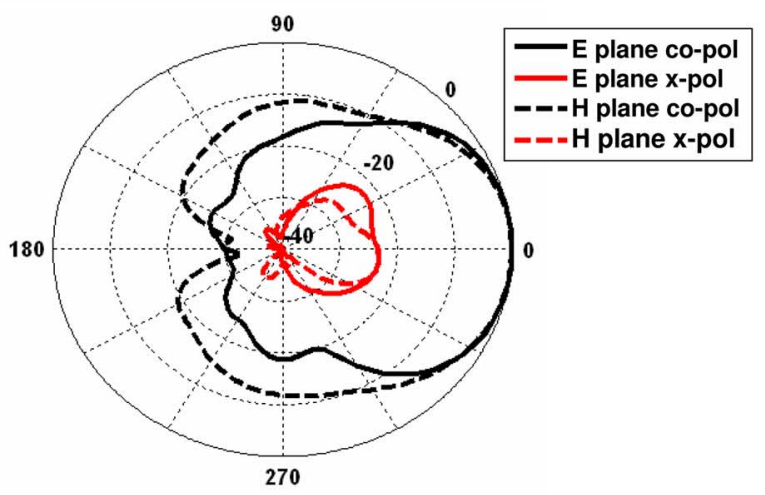

(b)

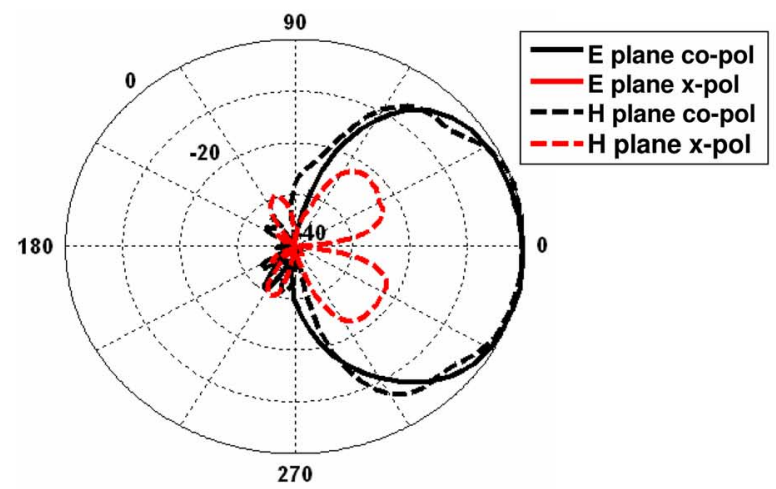

(c)

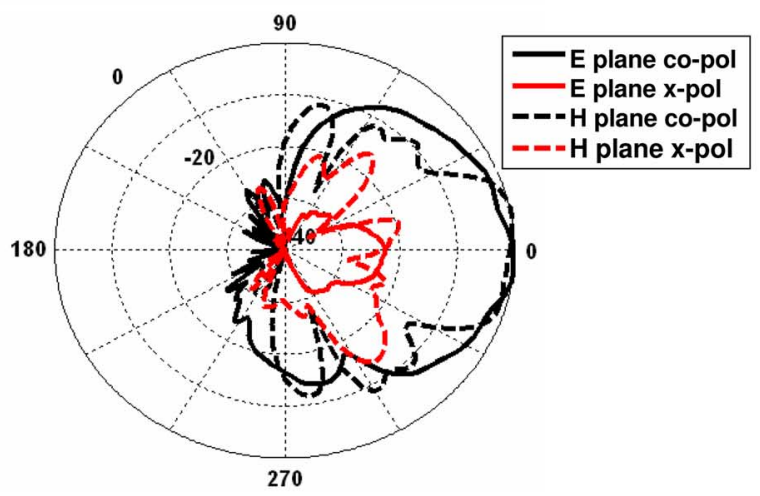

(d)

Fig. 7. Measured E plane (x-cut) and $\mathrm{H}$ plane (y-cut) patterns (a) $850 \mathrm{MHz}$ (b) $2 \mathrm{GHz}$, (c) $3.5 \mathrm{GHz}$, (d) $5.5 \mathrm{GHz}$ of the RAE.

formation in Fig. 4(b) shows an increasing grating lobe level in $\mathrm{B} 2$ as its dipole spacing, $\mathrm{Y}_{\mathrm{B} 2}$, increases. Based on these
TABLE II

Measured Worst Case Insertion Loss Between Two RADIATOR ELEMENTS

\begin{tabular}{ccccc}
\hline \hline & B1 freq & B2 freq & B3 freq & B4 freq \\
\hline B1 input & NA & $24 \mathrm{~dB}$ & $38 \mathrm{~dB}$ & $31 \mathrm{~dB}$ \\
B2 input & $33 \mathrm{~dB}$ & NA & $34 \mathrm{~dB}$ & $28 \mathrm{~dB}$ \\
B3 input & $62 \mathrm{~dB}$ & $17 \mathrm{~dB}$ & NA & $15 \mathrm{~dB}$ \\
B4 input & $48 \mathrm{~dB}$ & $25 \mathrm{~dB}$ & $36 \mathrm{~dB}$ & NA
\end{tabular}

analyses, a sidelobe level less than $10 \mathrm{~dB}$ and a radiation ripple of less than $4 \mathrm{~dB}$ is obtained for all four frequency bands.

After the optimized radiator spacing is obtained and the feeding network is included in the base board, the integrated balun dimensions are readjusted to accommodate the mutual coupling and power divider effects on the initial dipole impedance. $\mathrm{Hm}, \mathrm{Hs}$ and $\mathrm{Lm}$ are the three most significant dimensions when tuning the impedance bandwidth. In the equivalent circuit of the balun transition [16], $\mathrm{Hm}-\mathrm{Hs}$ determines the shorted slot stub length, $\mathrm{Hd}-\mathrm{Hm}$ determines the slot length, and $L m$ determines the microstrip stub length.

The measured and simulated results for return loss are shown in Figs. 5 and 6, featuring a value better than $10 \mathrm{~dB}$ in the frequency bands of interest. Passive antenna gains are measured in SATIMO and plotted in Figs. 5 and 6 . A value of $\sim 7-9 \mathrm{dBi}$ is observed at the center frequency for each frequency band. There is a maximum of $2 \mathrm{~dB}$ variation across a wide bandwidth. The measured radiation patterns are fairly constant across each frequency band as shown in Figs. 7. Less than $20 \mathrm{~dB}$ cross-polarization is achieved across all frequency bands to ensure the radiation linearity needed for base station. The simulated pattern matches that of the measurement. Due to the finite ground plane significant back radiation is observed for the pattern of $850 \mathrm{MHz}$. The ripples appearing at the radiation pattern for the highest frequency band (i.e., B4) are due to the higher order modes excited on the lower band dipoles.

Although the two radiator element is designed for switched frequency operations, investigation in its simultaneous frequency operation without the presence of the switch gives further insight in the element's performance. The isolation between the ports is critical in this case since one pair of radiator may increase the noise level received by other pairs due to higher order resonance and coupling. The minimum insertion loss, characterizing the worst case isolation, is summarized in Table II for each band of interest. Poor isolation from B1 to B2, $\mathrm{B} 3$ to $\mathrm{B} 2, \mathrm{~B} 3$ to $\mathrm{B} 4$, and from $\mathrm{B} 4$ to $\mathrm{B} 2$ indicates the need for isolating components such as switches or filters to reduce the noise formation.

\section{QuAD-BAnd Two Elements E-Plane ARRAY}

To demonstrate the capability of the quad-band two radiator element to extend to an array, a two-element array aligned in the $\mathrm{x}$ direction is presented in Fig. 8. For each frequency band, there are $2 \times 2$ dipoles; one dipole from each band is grouped in a quadrant to be fed by a switchable amplifier similar to an active integrated antenna topology. The novelty of the quad-band 


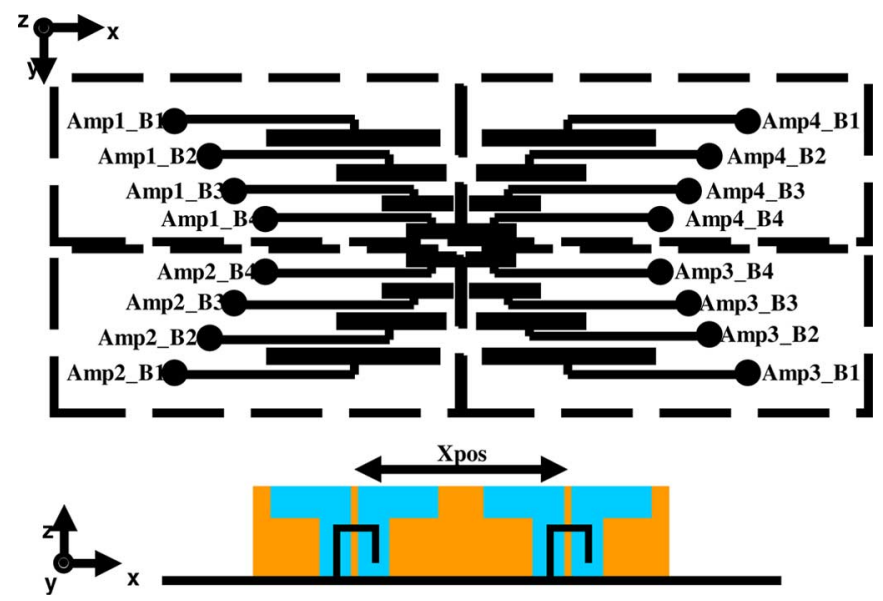

Fig. 8. Configuration of a quad-band antenna array.

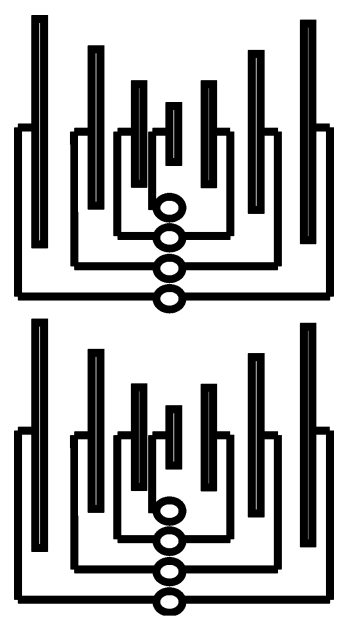

Fig. 9. An array of quad-band antenna element that would form grating lobes.

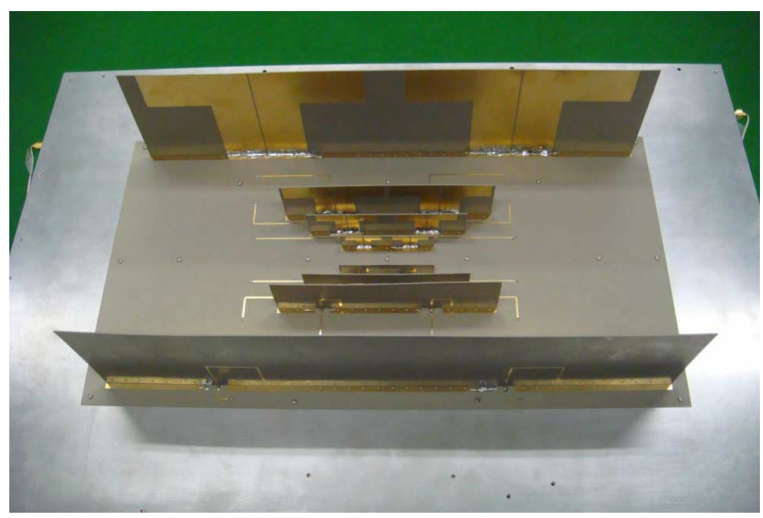

Fig. 10. A prototype of the quad-band antenna array.

antenna array lies in the use of additional symmetry enforcement in the $\mathrm{x}$ direction to achieve good uniformity of radiation pattern along its E-plane. The array is not the conventional array implementation such as the one shown Fig. 9. If the original quad-band antenna element is replicated and placed $0.5 \lambda$ (B1) from another element in the $\mathrm{x}$ direction like Fig. 9, strong
TABLE III

DIMENSIONS OF THE QUAD-BAND ANTENNA ARRAY (MM)

\begin{tabular}{ccccc}
\hline \hline Dimensions & B1 & B2 & B3 & B4 \\
\hline Hd & 95 & 40 & 25.2 & 15 \\
Ld & 170 & 76 & 45.6 & 27 \\
wd & 34 & 15 & 9 & 5.5 \\
wg & 68 & 30 & 18 & 11 \\
ws & 1 & 1 & 1 & 1 \\
Hs & 0 & 0 & 0 & 0 \\
Hm & 39.7 & 17.7 & 9.7 & 5.7 \\
wm & 1.7 & 1.7 & 1.7 & 1.7 \\
Wm & 36 & 16 & 11.6 & 8 \\
Lm & 26.7 & 16.7 & 5.2 & 5.5 \\
X & 200 & 80 & 60 & 35 \\
Y & 200 & 80 & 50 & 24
\end{tabular}

grating lobes will emerge at the higher frequency bands because the array separation at B1 is much larger than the free space wavelength of B3 and B4. This topology provides locality in the system level implementation while satisfying the array spacing requirement. It can be further extended to $\mathrm{n}$ elements along the $\mathrm{E}$ plane by symmetrically containing a pair of higher frequency elements between the lower ones. Unlike the quad-band element, no power splitter network was designed for the array due to the crowded base board spacing. For simplicity and without loss of generality, the design of the switchable amplifier will not be covered in this paper.

The quad-band antenna array was also built on the RF35 substrate. The dimensions of the quad-band antenna array are listed in Table III. A prototype of the quad-band antenna array with a $600 \mathrm{~mm} \times 400 \mathrm{~mm}$ ground plane is displayed in Fig. 10 .

To characterize the impedance matching, active driving impedance is measured to account for the mutual coupling between the four driven ports. In broadside operation where all ports are fed in-phase, the simulated and measured active driving impedance in Figs. 11 and 12 achieves $10 \mathrm{~dB}$ across the four frequency bands of interest. A Narda 4436-4 power divider was used to create in-phase feeding for the passive radiation pattern measurement in SATIMO. From the radiation patterns shown in Fig. 13, a more directive pattern is obtained in the E-plane compared to Figs. 7, with no significant grating lobe formation. High linearity is achieved by having less than $-20 \mathrm{~dB}$ of cross polarization. The antenna gains of the array shown in Figs. 11 and 12 are $9-11 \mathrm{dBi}$, about $2 \mathrm{~dB}$ higher than the individual antenna element. Note that the antenna gain was obtained by subtracting the power divider insertion loss.

The elements in the quad band array has a different alignment in the $\mathrm{x}$ direction from the original element, thus the mutual coupling between the radiators are different in the E-plane array configuration and needs to be revisited. In the array case, the highest coupling occurs within elements belonging to the same quadrant. With the minimum insertion loss of $11 \mathrm{~dB}$, the measured worst case isolation summarized in Table IV also indicates the need for isolators. 


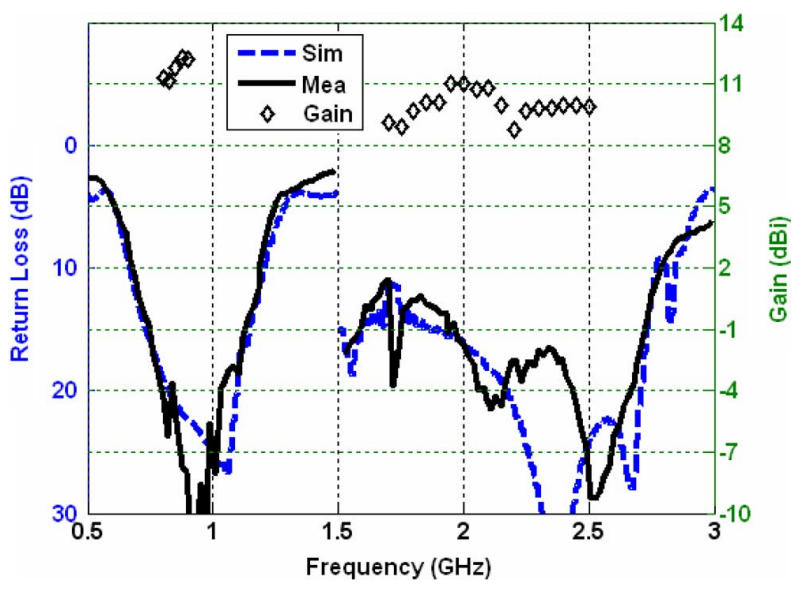

Fig. 11. Measured and simulated return loss with measured gain (passive) of the quad-band antenna array in B1 and B2.

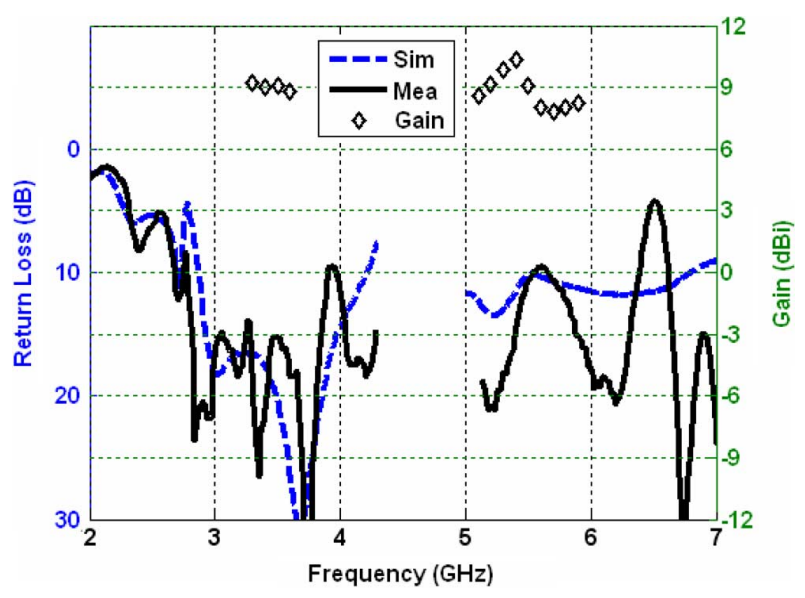

Fig. 12. Measured and simulated return loss with measured gain (passive) of the quad-band antenna array in B3 and B4.

TABLE IV

Measured Worst Case InSERTion Loss BetweEn 4 Elements in the SAME AMPLIFIER QUADRANT

\begin{tabular}{lcccc}
\hline \hline & B1 freq & B2 freq & B3 freq & B4 freq \\
\hline B1 input & NA & $25 \mathrm{~dB}$ & $26 \mathrm{~dB}$ & $37 \mathrm{~dB}$ \\
B2 input & $24 \mathrm{~dB}$ & $\mathrm{NA}$ & $19 \mathrm{~dB}$ & $28 \mathrm{~dB}$ \\
B3 input & $45 \mathrm{~dB}$ & $11 \mathrm{~dB}$ & $\mathrm{NA}$ & $28 \mathrm{~dB}$ \\
B4 input & $44 \mathrm{~dB}$ & $31 \mathrm{~dB}$ & $12 \mathrm{~dB}$ & $\mathrm{NA}$
\end{tabular}

\section{CONCLUSION}

Novel configurations of switchable quad-band two radiator elements and its extended array are proposed. Their operating frequencies cover all spectrums for existing wireless applications, such as GSM, PCS, WCDMA, WiFi, and WiMax. A consistent $\mathrm{H}$ plane pattern suitable for sectoring is achieved by the two radiator element across the four bands. The two element array demonstrates narrowing of E plane beam width for reducing the co channel interference between adjacent base stations. The quad-band array topology can be further extended
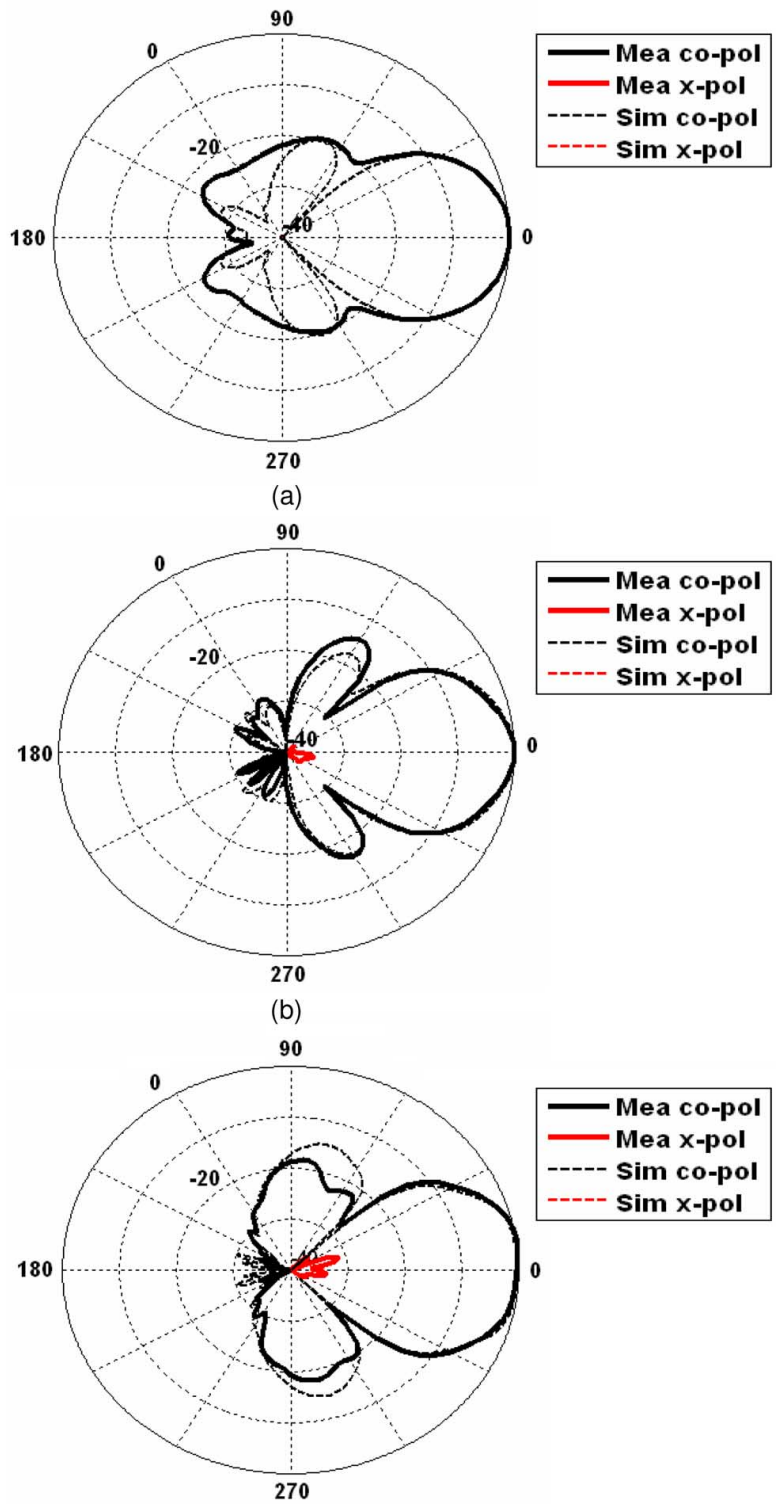

(c)

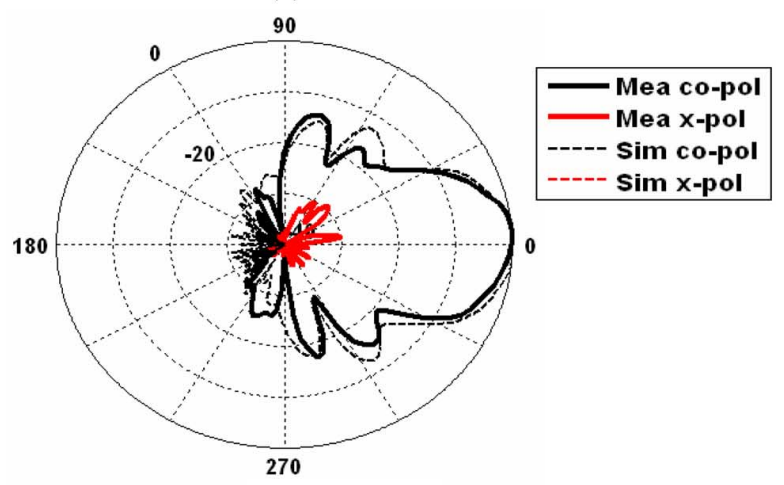

(d)

Fig. 13. Measured and simulated E-plane ( $\mathrm{x}-\mathrm{z}$ plane) radiation patterns of the quad-band antenna array. (a) $1 \mathrm{GHz}$. (b) $2 \mathrm{GHz}$. (c) $3.5 \mathrm{GHz}$. (d) $5.5 \mathrm{GHz}$.

along its E plane to reduce its vertical beam width, thus making the extension of this topology a suitable candidate for cognitive radio base station. 


\section{ACKNOWLEDGMENT}

The authors would like to thank K. Rutkowski of SATIMO Atlanta for the pattern measurements, Taconic Advance Dielectric Division for providing the substrate samples and CST Microstripes for its simulation capabilities. The authors also wish to acknowledge the support of the Georgia Electronic Design Center (GEDC).

\section{REFERENCES}

[1] J. Mitola, III, "Cognitive radio for flexible mobile multimedia communication," in Proc. IEEE Int. Workshop on Mobile Multimedia Coтmunications (MoМuC) 1999, Nov. 1999, pp. 3-10.

[2] K. Lim and J. Laskar, "Emerging opportunities of RF IC/system for future cognitive radio wireless communications," in Proc. IEEE Radio and Wireless Symp., Jan. 2008, pp. 703-706.

[3] P. S. Hall, P. Gardner, J. Kelly, E. Ebrahimi, M. R. Hamid, and F. Ghanem, "Antenna challenges in cognitive radio," presented at the Int. Symp. on Antennas and Propagation, Oct. 2008.

[4] M. K. Fries, M. Grani, and R. Vahldieck, "A reconfigurable slot antenna with switchable polarization," IEEE Microw. Wireless Compon. Lett., vol. 13, no. 11, pp. 490-492, Nov. 2003.

[5] B. A. Cetiner, H. Jafarkhani, J.-Y. Qian, H. J. Yoo, A. Grau, and F. De Flaviis, "Multifunctional reconfigurable MEMS integrated antennas for adaptive MIMO systems," IEEE Commun. Mag., vol. 42, no. 12, pp. 62-70, Dec. 2004.

[6] A. E. Fathy, A. Rosen, H. S. Owen, F. McGinty, D. J. McGee, G. C. Taylor, R. Amantea, P. K. Swain, S. M. Perlow, and M. ElSherbiny, "Silicon-based reconfigurable antennas-concepts, analysis, implementation, and feasibility," IEEE Trans. Microw. Theory Tech., vol. 51, no. 6, pp. 1650-1661, Jun. 2003.

[7] C. Zhang, S. Yang, H. K. Pan, A. E. Fathy, S. El-Ghazaly, and V. Nair, "Reconfigurable antenna for simultaneous multi-service wireless applications," in Proc. IEEE Radio and Wireless Symp., Jan. 9-11, 2007, pp. 543-546.

[8] L. N. Pringle, P. H. Harms, S. P. Blalock, G. N. Kiesel, E. J. Kuster, P. G. Friederich, R. J. Prado, J. M. Morris, and G. S. Smith, "A reconfigurable aperture antenna based on switched links between electrically small metallic patches," IEEE Trans. Antennas Propag., vol. 52, no. 6, pp. 1434-1445, Jun. 2004.

[9] A. Mirkimali and P. S. Hall, "Log periodic printed dipole array for wideband frequency reconfiguration," presented at the IET Seminar on Wideband/Multiband Antennas and Arrays for Civil or Defence Applications, London, Mar. 13, 2008.

[10] S. Zhang, G. H. Huff, J. Feng, and J. T. Bernhard, "A pattern reconfigurable microstrip parasitic array," IEEE Trans. Antennas Propag., vol. 52, no. 10, pp. 2773-2776, Oct. 2004.

[11] C. Alakija and S. P. Stapleton, "A mobile base station phased array antenna," presented at the Int. Conf. on Selected Topics in Wireless Communications, Vancouver, Jun. 1992.

[12] C. A. Balanis, Antenna Theory: Analysis and Design, 3rd ed. Hoboken, NJ: Wiley, 2005, pp. 946-951.

[13] S. K. Palit and A. Hamadi, "Design and development of wideband and dual-band microstrip antennas," IEE Proc.-Microw. Antennas Propag., vol. 146, no. 1, pp. 35-39, Feb. 1999.

[14] F. Tefiku and C. A. Grimes, "Design of broad-band and dual-band antennas comprised of series-fed printed-strip dipole pairs," IEEE Trans. Antennas Propag., vol. 48, no. 6, pp. 895-900, Jun. 2000.

[15] P. Li, K. M. Kuk, and K. L. Lau, "A dual-feed dual-band L-probe patch antenna," IIEEE Trans. Antennas Propag., vol. 53, no. 7, pp. 2321-2323, Jul. 2005.

[16] R. L. Li, B. Pan, T. Wu, K. Lim, J. Laskar, and M. M. Tentzeris, "Equivalent-circuit analysis and design of a broadband printed dipole with adjusted integrated balun and a printed array for base station applications," IEEE Trans. Antennas Propag., vol. 57, no. 7, Jul. 2009.

[17] C. Ha, Y. Qian, and T. Itoh, "A modified Quasi-Yagi planar antenna with wideband characteristics in C-band," in Proc. IEEE Antennas and Propagation Society Int. Symp., Jul. 8-13, 2001, vol. 3, pp. 154-157.

[18] H. K. Kan, R. B. Waterhouse, A. M. Abbosh, M. E. Bialkowski, and K. L. Chung, "A simple broadband planar Quasi-Yagi antenna," presented at the IEEE TENCON, Nov. 14-17, 2006.

[19] B. Edward and D. Rees, "A broadband printed dipole with integrated balun," Microw. J., pp. 339-344, May 1987.

[20] P. Lindberg, E. Ojefors, Z. Barna, A. Thornell-Pers, and A. Rydberg, "Dual wideband printed dipole antenna with integrated balun," IET Microw. Antennas Propag., vol. 1, no. 3, pp. 707-711, Jun. 2007.

[21] E. R. Brown, "RF-MEMS switches for reconfigurable integrated circuits," IEEE Trans. Microw. Theory Tech., vol. 46, no. 11, pp. 1868-1880, Nov. 1998.

[22] T. A. Milligan, Modern Antenna Design, 2nd ed. New York: McGraw-Hill, 2005, pp. 106-107.

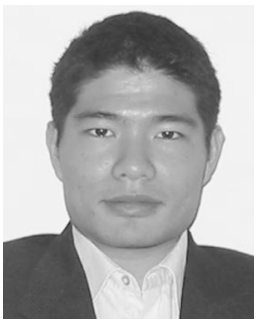

Award.
Terence Wu (S'05) received the B.S. degree in electrical engineering from Georgia Institute of Technology in 2005. He is currently working toward the Ph.D. degree in electrical engineering under Dr. Tentzeris.

His research interests include antenna miniaturization for portable electronics, multiband array integration, antennas integration/packaging for wireless sensor nodes and RFID technology.

$\mathrm{Mr}$. Wu was the recipient of the 2009 IEEE APS Symposium Student Paper Honorable Mention

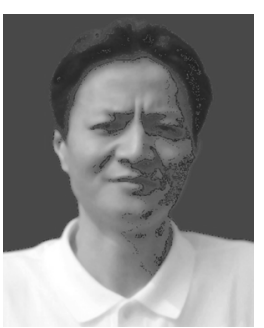

Rong Lin Li (M'02-SM'03) received the B.S. degree in electrical engineering from Xi' an Jiaotong University, China, in 1983, and the M.S. and Ph.D. degrees in electrical engineering from Chongqing University, in 1990 and 1994, respectively.

From 1983 to 1987, he worked as an Assistant Electrical Engineer in Yunnan Electric Power Research Institute. From 1994 to 1996, he was a Postdoctoral Research Fellow in Zhejiang University, China. In 1997, he visited Hosei University, Japan, as an HIF (Hosei International Fund) Research Fellow. In 1998, he became a Professor in Zhejiang University. In 1999, he visited the University of Utah, as a Research Associate. In 2000, he worked as a Research Fellow at the Queen's University of Belfast, UK. Since 2001, he has been a Research Scientist at Georgia Tech. He is now an Endowed Professor in the South China University of Technology and in part with the Georgia Tech. He has published more than 100 papers in refereed Journals and Conference Proceedings, and three book chapters. His current research interests include new design techniques for antennas in mobile and satellite communication systems, phased arrays and smart antennas for radar applications, wireless sensors and RFID technology, electromagnetics and information theory.

Dr. Li is a member of the IEEE International Compumag Society. He was a member of the Technical Program Committee for IEEE-IMS 2008 and 2009 Symposia and a session chair for several IEEE-APS Symposia. He was the recipient of the 2009 Georgia Tech-ECE Research Spotlight Award. He currently serves as an Editor of the ETRI Journal and a reviewer for a number of international journals, including IEEE TRANSACTIONS ON ANTENNAS AND PROPAgATION, IEEE ANTENNAS AND WiRELESS PROPAGATION LETTERS, IEEE MicrowaVE AND Wireless COMPONENTS LETTERS, and IET Microwave, Antennas and Propagation, Progress in Electromagnetic Research, Journal of Electromagnetic Waves and Applications, and International Journal of Wireless Personal Communications.

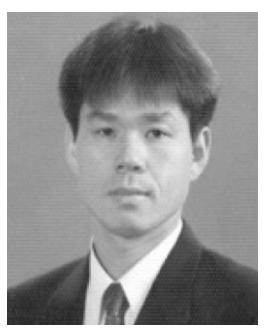

Soon-Young Eom (M'01) was born in Gangwon-do, Korea, on May 2, 1964. He received the B.S., M.S., and the $\mathrm{Ph} . \mathrm{D}$. degrees in electronic engineering from Yonsei University, Seoul, Korea, in 1988, 1990 and 2003, respectively.

Since 1990, he has worked at Electronics and Telecommunications Research Institute (ETRI), Daejeon (Korea) as a Principal Member of research staff. From 1991 to 1993, he participated in the joint project with Alenia Spazio S.p.A in Italy, for developing the very small aperture terminal (VSAT) demand assignment multiple access (DAMA-SCPC) system. From 1996 to 2006, he took part in developing mobile active phased array antenna systems for direct broadcasting satellite (DBS) reception and satellite communications. $\mathrm{He}$ also developed the reconfigurable antenna/RF integration technology jointly with Georgia Technology Research Corporation, from July 2007 to July 2008. Since 2007, he has been developing an intelligent antenna system for mobile base station. His research interests include active phased array antenna systems, microwave circuits and systems. 


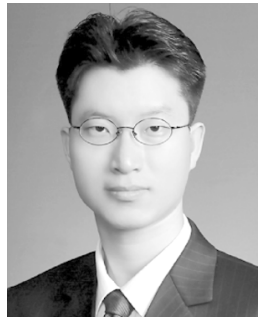

Seong-Sik Myoung (S'02-M'10) was born in Taean, Korea. He received the B.S. degree in electronics engineering from Soongsil University, Seoul, in 2002 and the M.S. and Ph.D. degrees in electrical and electronic engineering from Yonsei University, Seoul, Korea, in 2004 and 2009, respectively.

He was a visiting scholar at Georgia Institute of Technology from 2007 to 2008 . He is currently working on Samsung Electronics Inc., South Korea, as a Senior Engineer. His current research interests include GaAs HBT based monolithic-microwave/millimeter-wave integrated circuit design, microwave filter design, communication system design and analysis, and CMOS RF/Analog integrated circuit design.

Dr. Myoung is a recipient of the Seoul Science Fellowship from Seoul Metropolitan government in 2005, the Bellwave Best Paper Award from Korea Electromagnetic Engineering Society in 2005, the Best Presentation Paper Award from Korea Electromagnetic Engineering Society in 2006, and the IEEE Student Paper Contest from the IEEE Seoul Chapter in 2006. He was selected by Brain Korea 21 of the Korean government and received financial support for his collaboration with the Georgia Institute of Technology in 2007. He received the TMS Best Paper Award from Yonsei University in 2007 and the IEEE Best Award IEEE Seoul Chapter in 2008. He is a finalist and honorable mentioned of International Microwave Symposium of IEEE MTT Society in 2008.

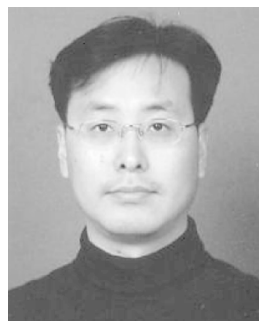

Kyutae Lim (M'93) was born in Seoul, Korea, in 1968. He received the B.S., M.S. and Ph.D. degrees from the Hanyang University, Seoul, Korea, in 1991, 1993 and 1996, respectively.

From 1996 to 2000, he was with the Samsung Advance Institute of Technology, Kiheung, Korea, as a member of technical staff. From 1998 to 1999, was with the Communication Research Lab, Tokyo, Japan, as a Research Fellow. In January 2000, he joined Microwave Application Group in Georgia Institute of Technology as a Senior Research Engineer. Currently he is serving as Associate Director of Technology of Georgia Electronic Design Center (GEDC) at Georgia Institute of Technology. Current technical projects that he is leading and co-leading are Cognitive Radio and Digital Transmitter/Receiver. His research interests include the cognitive radio based wireless communication system and enabling technology, RF/Analog circuit and system for wireless and high-speed system applications. He has authored and co-authored over 100 journal and proceeding papers and holding four patents. He has been invited as speakers of numerous workshops, conferences, regulations and standardization bodies for more than 15 times.

Dr. Lim is currently serving as the Convener of TC 48-TG 1, the wireless standard for the white space application, in European Computer Manufactures Association International. He has been serving as a Technical Program Committees for numerous international conferences, including International Microwave Symposium, Cognitive Radio Oriented Wireless Network Conference, and Globecom and Vehicular Technology Conference. He is a member of the IEEE Microwave Theory and Technique (MTT), Communication Society (ComSoc), Antennas and Propagation (AP), Signal Processing (SP), Technical Committee of Cognitive Network in ComSoc.

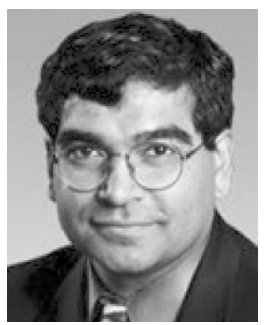

Joy Laskar (S'84-M'85-SM'02-F'05) received the B.S. degree (computer engineering with math/physics minors, summa cum laude) from Clemson University in 1985, and the M.S. and the Ph.D. degrees in electrical engineering from the University of Illinois at Urbana-Champaign, in 1989 and 1991, respectively.

Prior to joining Georgia Tech in 1995, he was a Visiting Professor at the University of Illinois at Urbana-Champaign, and an Assistant Professor at the University of Hawaii at Manoa. At Georgia Tech he holds the Schlumberger Chair in Microelectronics in the School of Electrical and Computer Engineering. He is also Founder and Director of the Georgia Electronic Design Center, and he heads a research group of 50 members (graduate students, research staff and administration) with a focus on integration of high-frequency mixed-signal electronics for next-generation wireless and wire line systems. Between 1995 and Spring 2008, he graduated 34 Ph.D. students.
He has authored or coauthored more than 500 papers, several book chapters and three books (with another book in development). He has given numerous invited talks, and he has more than 40 patents issued or pending. His work has resulted in the formation of two companies. In 1998, he co-founded an advanced WLAN IC Company: RF Solutions, which is now part of Anadgics (Nasdaq: Anad) In 2001, he co-founded a next-generation analog CMOS IC company, Quellan, which is developing collaborative signal-processing solutions for the enterprise, video, storage and wireless markets.

Dr. Laskar's honors include the Army Research Office's Young Investigator Award in 1995, the National Science Foundation's CAREER Award in 1996, NSF Packaging Research Center Faculty of the Year in 1997, and co-recipient of the IEEE Rappaport Award (Best IEEE Electron Devices Society Journal Paper) in 1999. He was faculty advisor for the 2000 IEEE MTT IMS Best Student Paper award, was Georgia Tech Faculty Graduate Student Mentor of the year in 2001, received a 2002 IBM Faculty Award, and the 2003 Clemson University College of Engineering Outstanding Young Alumni Award. He was the 2003 recipient of the Outstanding Young Engineer award of the Microwave Theory and Techniques Society and was named an IEEE Fellow in 2005. For the 2004-2006 term, he served as an IEEE Distinguished Microwave Lecturer and currently is an IEEE EDS Distinguished Lecturer. He received Georgia Tech's Outstanding Faculty Research Author Award in 2007 and ECE's Distinguished Mentor Award in 2008. He served as General Chairman of the IEEE International Microwave Symposium in 2008.

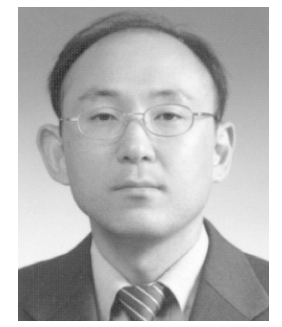

Soon Ik Jeon received the B.S. and M.S. degrees in electronic engineering from Korea University, in 1984 and 1996, respectively, and the Ph.D. degree in electronic engineering from Chung-Nam University, in 2003

From 1984 to 1990, he worked at Samsung Electronics as a member of research staff. Since 1990, he is working at the Electronics and Telecommunications Research Institute (ETRI), Daejeon, Korea. $\mathrm{He}$ is a head of Antenna Research Team at Radio Technology Research Department in ETRI. He was involved in the development of the VSAT system and the Satellite Paging Earth Station. He has been involved to develop mobile active phased array antenna systems for DBS reception and satellite communications. He is now involved to develop base station antennas for wireless communications. His research interests include active phased array antenna systems and applications of $M / W$ technologies.

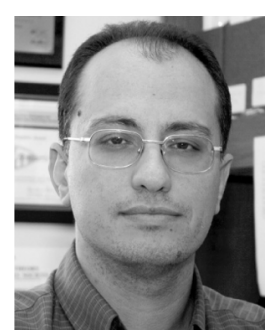

Manos M. Tentzeris (SM'03-F'09) received the Diploma Degree in electrical and computer engineering from the National Technical University of Athens (magna cum laude) in Greece and the M.S. and $\mathrm{Ph} . \mathrm{D}$. degrees in electrical engineering and computer science from the University of Michigan, Ann Arbor

$\mathrm{He}$ is currently a Professor with School of ECE Georgia Tech, Atlanta. He has published more than 320 papers in refereed Journals and Conference Proceedings, three books and 17 book chapters. He has helped develop academic programs in Highly Integrated/Multilayer Packaging for RF and Wireless Applications using ceramic and organic flexible materials, paper-based RFID's and sensors, Microwave MEM's, SOP-integrated (UWB, mutliband, conformal) antennas and Adaptive Numerical Electromagnetics (FDTD, MultiResolution Algorithms) and heads the ATHENA research group (20 researchers). He is the Georgia Electronic Design Center Associate Director for RFID/Sensors research, and he has been the Georgia Tech NSF-Packaging Research Center Associate Director for RF Research and the RF Alliance Leader from 2003-2006.

Dr. Tentzeris was the recipient/co-recipient of the 2009 E. T. S. Walton Award from the Irish Science Foundation, the 2007 IEEE APS Symposium Best Student Paper Award, the 2007 IEEE IMS Third Best Student Paper Award, the 2007 ISAP 2007 Poster Presentation Award, the 2006 IEEE MTT Outstanding Young Engineer Award, the 2006 Asian-Pacific Microwave Conference Award, the 2004 IEEE TRANSACTIONS ON ADVANCED PACKAGING Commendable Paper Award, the 2003 NASA Godfrey "Art" Anzic Collaborative Distinguished Publication Award, the 2003 IBC International Educator of the Year Award, the 2003 IEEE CPMT Outstanding Young Engineer Award, the 2002 International Conference on Microwave and Millimeter-Wave Technology Best Paper Award (Beijing, CHINA), the 2002 Georgia Tech-ECE Outstanding Junior Faculty 
Award, the 2001 ACES Conference Best Paper Award and the 2000 NSF CAREER Award and the 1997 Best Paper Award of the International Hybrid Microelectronics and Packaging Society. He was the TPC Chair for IEEE IMS 2008 Symposium and the Chair of the 2005 IEEE CEM-TD Workshop and he is the Vice-Chair of the RF Technical Committee (TC16) of the IEEE CPMT Society. He is the founder and chair of the RFID Technical Committee (TC24) of the IEEE MTT Society and the Secretary/Treasurer of the IEEE C-RFID. He has organized various sessions and workshops on RF/Wireless Packaging and Integration, RFID's, Numerical Techniques/Wavelets, in IEEE ECTC, IMS, VTC and APS Symposia in all of which he is a member of the Technical Program Committee in the area of "Components and RF." He is an Associate
Editor of the IEEE TRANSACTIONS ON MicrowaVE THEORY AND TECHNIQUES, IEEE TRANSACTIONS ON ADVANCED PACKAGING and the International Journal on Antennas and Propagation. He was a Visiting Professor with the Technical University of Munich, Germany for the summer of 2002, where he introduced a course in the area of high-frequency packaging. He has given more than 80 invited talks in the same area to various universities and companies in Europe, Asia and America. He is a Fellow of IEEE, a member of URSI-Commission D, a member of MTT-15 committee, an Associate Member of EuMA, a Fellow of the Electromagnetic Academy and a member of the Technical Chamber of Greece. He is the IEEE MTT-S Distinguished Microwave Lecturer from 2010-2012. 